Disclosure of Interests: Tjardo Maarseveen: None declared, Marc Maurits: None declared, Ellis Niemantsverdriet: None declared, Thomas Huizinga Grant/ research support from: Ablynx, Bristol-Myers Squibb, Roche, Sanofi, Consultant of: Ablynx, Bristol-Myers Squibb, Roche, Sanofi, Annette van der Helm - van Mil: None declared, Rachel Knevel: None declared

DOI: 10.1136/annrheumdis-2020-eular.5647

\section{AB1115 REAL-WORLD NAILFOLD VIDEOCAPILLAROSCOPY IN A REFERRAL CENTER IN NORTHWESTERN COLOMBIA: A RETROSPECTIVE COHORT STUDY}

D. C. Varela Tabares ${ }^{1}$, J. Gutiérrez Bolaños ${ }^{1}$, L. M. Rodríguez Padilla ${ }^{2}$, M. A. Mesa Navas ${ }^{3,4}$, C. J. Velásquez-Franco ${ }^{3,4}$ on behalf of EULAR Study Group on Microcirculation in Rheumatic Diseases.. UNIR Research Group. School of Health Sciences. Universidad Pontificia Bolivariana. Medellin, Colombia

${ }^{1}$ Universidad Pontificia Bolivariana, Internal Medicine, Medellin, Colombia;

${ }^{2}$ Universidad Pontificia Bolivariana, Research, Medellin, Colombia;

${ }^{3}$ Universidad Pontificia Bolivariana. Clinica Universitaria Bolivariana, Rheumatology, Medellin, Colombia; ${ }^{4}$ EULAR Study Group on Microcirculation in Rheumatic Diseases, Medellin, Colombia

Background: Nailfold videocapillaroscopy is a non-invasive tool for the assessment of peripheral microcirculation, and it is useful for the diagnosis and prognosis of systemic autoimmune diseases. Despite its frequent use in clinical practice, the indications of this procedure are not standardized and there is no clear information in real-life about the reasons for remission, the presence of clinical findings of autoimmune diseases during the procedure, the frequency of patterns of autoantibodies and specific capillaroscopic findings.

Objectives: To describe the sociodemographic, clinical, paraclinical, and capillaroscopic findings of a cohort of subjects referred to a capillaroscopy service in northwestern Colombia.

Methods: We conducted a retrospective cohort study, including subjects from 2015 to 2018. Patients were evaluated by two expert rheumatologists. Variables: Reasons for referral, capillaroscopic patterns at baseline and at 6-month follow-up, presence of clinical findings of systemic autoimmune diseases during the procedure (Raynaud's phenomenon, puffy fingers, sclerodactyly, pitting scars, digital ulcers, sclerosis cutis, platysma sign, Gottron, and microstomy), along with the pattern and dilution of antinuclear antibodies. Categorical variables were expressed in frequency and percentage and quantitative variables in mean and standard deviation or median with interquartile range, depending on the distribution of the data. Statistical package: SPSS 25. This survey was approved by the institutional Ethics Committee.

Results: A total of 392 capillaroscopies were performed, 318 for the first time. The referral reasons for capillaroscopy were: Raynaud's phenomenon ( $n=134 ; 42.1 \%)$, connective tissue disease different than systemic sclerosis (SSc) ( $n=105 ; 33.1 \%)$, and systemic sclerosis $(n=79 ; 24.8 \%)$. The baseline capillaroscopic patterns found were: Normal $(n=123 ; 38.7 \%)$, non-specific $(n=81 ; 25.5 \%)$, SSc $(n=90 ; 28.3 \%)$, scleroderma-like ( $n=24 ; 7.5 \%)$. Among SSc pattern, early $(21 / 90 ; 23.3 \%)$, active, $(38 / 90 ; 42.2 \%)$, and late patterns $(31 / 90 ; 34.4 \%)$ were found. Of the 12 capillaroscopies that presented a non-specific pattern at 6-month follow-up, only one (8.3\%) progressed to a systemic sclerosis pattern. In the SSc patterns, the frequency of clinical findings were: sclerodactyly ( $n=34 ; 37.8 \%)$, Raynaud`s phenomenon $(n=26$; $28.9 \%)$, puffy fingers $(n=10 ; 11.1 \%)$, platysma sign $(n=10 ; 11.1 \%)$, pitting scars $(n=8 ; 8.9 \%)$, digital ulcers $(n=8 ; 8.9 \%)$, telangiectasia $(n=7 ; 7.8 \%)$, microstomy $(n=4 ; 4.4 \%)$, and Gottron $(n=1 ; 1.1 \%)$. In the SSc patterns, $42 / 44$ subjects $(95,4 \%)$ had positive antinuclear antibodies in an mean dilution of $1: 320$; the most frequent patterns were: centromere $(n=27 ; 64.3 \%)$ and nucleolar $(n=6 ; 14-3 \%)$.

Conclusion: In a real-world setting, the main referral reason to a capillaroscopic center was Raynaud's phenomenon; more than a third of the subjects had normal capillaroscopic findings; in the subgroup of baseline non-specific pattern, most of them were normal during follow-up; sclerodactyly and Raynaud's phenomenon were the most frequent clinical findings in patients with systemic sclerosis capillaroscopic patterns.

References:

[1] Melchor S, et al. Semin Arthritis Rheum. 2016; 46(3): 350-5.

[2] Fichel F, et al. Dermatology. 2014;228(4): 360-7

Acknowledgments: School of Health Sciences. Universidad Pontificia Bolivariana. Clinica Universitaria Bolivariana. Medellin, Colombia

Disclosure of Interests: None declared

DOI: 10.1136/annrheumdis-2020-eular.1436

\section{AB1116 DOPPLER EVALUATION OF ENTHESITIS SEEMS TO BE A RELEVANT OUTCOME IN THE ASSESSMENT OF ACTIVITY IN SPONDYLOARTHRITIS AND PSORIATIC ARTHRITIS}

J. Molina Collada ${ }^{1}$, C. Macía-Villa ${ }^{2}$, C. Plasencia ${ }^{3}$, J. M. Alvaro-Gracia ${ }^{1}$, E. De Miguel ${ }^{3} .{ }^{1}$ Hospital Universitario Gregorio Marañón, Madrid, Spain; ${ }^{2}$ Hospital
Universitario Severo Ochoa, Madrid, Spain; ${ }^{3}$ Hospital Universitario La Paz, Madrid, Spain

Background: The assessment of activity in spondyloarthritis (SpA) and psoriatic arthritis (PsA) involves several domains, including enthesitis. Clinical enthesitis evaluation has shown low sensitivity, specificity and reliability. Ultrasound (US) examination of enthesitis can be an accurate and objective way to evaluate this domain, supporting its inclusion in the assessment of the global state of the disease

Objectives: The main objective of this study is to analyze de prevalence of Doppler enthesitis in active SpA and PsA patients and to evaluate its association with the disease activity at patient level prior to start a biological therapy

Methods: A prospective multicenter cross-sectional study in patients with SpA and PsA with active disease (defined as patients who were going to start or switch biological therapy according to physician criteria and in agreement with clinical guidelines) was undertaken. Basal assessment included clinical features, physical examination and laboratory tests. Patients underwent bilateral US examination of peripheral entheses according to the MAdrid Sonographic Enthesitis Index (MASEI). MASEI and Outcome Measures in Rheumatology (OMERACT) enthesitis Power Doppler (PD) definitions were checked. Each enthesis was scanned in two planes: longitudinal and transverse, and 5 second videos were recorded for reliability. An inter-reader analysis by three readers was performed at each included center. For statistical analysis Mann-WhitneyU and Kruskal-Wallis tests were used. Intraclass correlation coefficient (ICC) and kappa test were used for reliability

Results: 64 consecutive patients were included, of whom 19(29.7\%) were ankylosing spondylitis (AS), $7(10.9 \%)$, non-radiographic axial spondyloarthritis (nr-axSpA) and $38(59.4 \%)$ PsA patients. Mean age was $52.4 \pm 12.5$ years and $36(56.3 \%)$ were males. Mean DAS28 $(3.6 \pm 1.3)$ for peripheral involvement, mean BASDAI $(5.6 \pm 2.2)$ for axial involvement, and CRP values $(10 \pm 10.9)$ reflect moderate-high disease activity at baseline. Demographic, clinical and MASEI baseline characteristics are shown in Table 1. Mean global MASEI score was $29.4( \pm 11.4)$ and 55 patients $(86 \%)$ scored $\geq 18$ (proposed cut-off point to diagnose SpA). At the patient level, abnormal US findings consistent with at least one enthesis showing PD signal were observed in 52(81.3\%) of patients using MASEI PD and $48(75 \%)$ using OMERACT PD definition without significant variation among the different $\mathrm{SpA}$ subtypes ( $\mathrm{p}=0.8$ and $p=0.6$, respectively). The inter-reader reliability among the two cohorts from each center performed by three readers was high (ICC cohort 1:0.92; cohort 2:0.85) and inter three readers kappa was good (0.92 and 0.86 for Doppler MASEI and Doppler OMERACT respectively).

Table 1. Baseline characteristics of SpA and PsA patients

\begin{tabular}{|c|c|c|c|c|c|}
\hline & $\begin{array}{c}\text { Total } \\
\mathrm{n}=64\end{array}$ & $\begin{array}{c}\text { AS } \\
n=19 \\
(29.7 \%)\end{array}$ & $\begin{array}{c}\text { PsA } \\
n=38 \\
(59.4 \%)\end{array}$ & $\begin{array}{c}\text { nr-axSpA } \\
n=7 \\
(10.9 \%)\end{array}$ & $\mathrm{p}$ \\
\hline Age & $52.4 \pm 12.5$ & $50.3 \pm 14.5$ & $54.6 \pm 11.6$ & $46.3 \pm 9.9$ & 0.2 \\
\hline Sex (Male) & $36(56.3 \%)$ & $10(52.6 \%)$ & $23(60.5 \%)$ & $3(42.9 \%)$ & 0.6 \\
\hline $\mathrm{CRP}(\mathrm{mg} / \mathrm{L})$ & $10 \pm 10.9$ & $13.7 \pm 11.4$ & $9 \pm 10.9$ & $6.8 \pm 9.1$ & 0.3 \\
\hline VSG $(\mathrm{mm} / \mathrm{h})$ & $17.3 \pm 15$ & $12.6 \pm 7.5$ & $20.6 \pm 18$ & $11.9 \pm 4$ & 0.4 \\
\hline DAS28 $n=40$ & $3.6 \pm 1.3$ & $3.1 \pm 1.1$ & $3.9 \pm 1.3$ & $3.2 \pm 1.4$ & 0.2 \\
\hline BASDAI $n=23$ & $5.6 \pm 2.2$ & $5.3 \pm 2.5$ & $5.4 \pm 0.8$ & $6.9 \pm 0.9$ & 0.2 \\
\hline MASES $n=26$ & $1.1 \pm 1.5$ & $1.1 \pm 1.6$ & - & $1.1 \pm 1.3$ & 0.9 \\
\hline MASEI & $29.4 \pm 11.4$ & $29.1 \pm 9$ & $30 \pm 12.8$ & $26.7 \pm 10.4$ & 0.9 \\
\hline MASEI score $\geq 18$ & $55(85.9 \%)$ & $18(94.7 \%)$ & $32(84.2 \%)$ & $5(71.4 \%)$ & 0.3 \\
\hline $\begin{array}{l}\text { Mean number of enthesis with PD } \\
\text { OMERACT }\end{array}$ & $1.6 \pm 1.4$ & $1.7 \pm 1.3$ & $1.5 \pm 1.5$ & $1.6 \pm 1.7$ & 0.6 \\
\hline $\begin{array}{l}\text { Mean number enthesis with PD } \\
\text { MASEI }\end{array}$ & $2.1 \pm 1.7$ & $1.9 \pm 1.4$ & $2.2 \pm 1.8$ & $1.7 \pm 1.7$ & 0.8 \\
\hline PD OMERACT $\geq 1$ & $48(75 \%)$ & $15(78.9 \%)$ & $28(73.7 \%)$ & $5(71.4 \%)$ & 0.9 \\
\hline PD MASEI $\geq 1$ & $52(81.3 \%)$ & $15(78.9 \%)$ & $32(84.2 \%)$ & $5(71.4 \%)$ & 0.7 \\
\hline
\end{tabular}

Conclusion: $\mathrm{PD}$ enthesitis is found in the vast majority of patients with active SpA and PsA, independent of SpA subtype. MASEI PD might have some advantages versus OMERACT PD definition to detect active enthesitis. These findings support the usefulness of PD US in the assessment of activity in SpA and PsA at patient level.

Disclosure of Interests: Juan Molina Collada: None declared, Cristina MacíaVilla: None declared, Chamaida Plasencia: None declared, Jose-Maria Alvaro-Gracia Grant/research support from: Abbvie, Elli-Lilly, MSD, Novartis, Pfizer, Consultant of: Abbvie, BMS, Janssen-Cilag, Elli-Lilly, MSD, Novartis, Pfizer, Sanofi, Tigenix, Roche, UCB, Paid instructor for: Elli-Lilly, Pfizer, Roche, Speakers bureau: Abbvie, BMS, Janssen-Cilag, Elli-Lilly, Gedeon Richter, MSD, Novartis, Pfizer, Sanofi, Tigenix, Roche, UCB, Eugenio de Miguel Grant/research support from: Yes (Abbvie, Novartis, Pfizer), Consultant of: Yes (Abbvie, Novartis, Pfizer), Paid instructor for: yes (AbbVie, Novartis, Pfizer, MSD, BMS, UCB Roche, Grunental, Janssen, Sanofi), Speakers bureau: yes (AbbVie, Novartis, Pfizer, MSD, BMS, UCB, Roche, Grunental, Janssen, Sanofi) DOI: 10.1136/annrheumdis-2020-eular.4867 